\title{
Constructing open teaching platform based on Internet
}

\author{
Haifeng Tang \\ School of Life Science, \\ Jilin University, \\ Jilin, 130012, China \\ E-mail:tanghf@jlu.edu.cn
}

\author{
Ying Liu \\ Jilin Science and Technology \\ Vocation College, \\ Jilin, 130123, China \\ E-mail:liuy@163.com
}

\author{
Deli Wang, Qingfan Meng, Lirong Teng \\ School of Life Science, \\ Jilin University, \\ Jilin, 130012, China \\ E-mail:wangdl@jlu.edu.
}

\begin{abstract}
In order to solve the problem that on-line opening courses, in China, are hardly attractive to students, this paper present a multiple workflow and method of constructing open teaching platform. A series of quality factors are analyzed, such as the technical ability of members in making team and ideas of designing platform, the performance of selected cameras, decorating of special classroom, the content of manuscripts, the technique of filming and editing, the frame of website and the method of uploading files, and then a best solution are provided. For illustration, a survey among students is carried out to certify the attraction of the teaching platform produced according the recommended workflow and method. Empirical results show that the teaching platform generated with methods in this paper has exhibited more attraction to the Chinese students. The workflow which is a valuable benchmark to teacher who want to make opening course or MOOC have solved better the problem of lacking attraction in Chinese on-line opening courses.
\end{abstract}

Keywords-information technonlogy; teaching platform; opening course; workflow;

\section{INTRODUCTION}

Information technology is a synthesis consisting of computer technology, network technology and communication technology, at present. And information technology has already became the main leading development field of science and technology, which have already effected the every aspect in our society deeply and extensively and have been permeating and changing our living. Information technology have served as the tools of finding or inquiring, discussing and communicating, innovating and knowledge architecture, and acquiring resource and content of the lessons in higher education [1]. Since 2001, Massachusetts Institute of Technology carried out the plan of opening courseware on the internet firstly, information technology had become an advanced way of teaching, which could turn the limited opening of teaching resource into sufficient opening and, further more, promote that exploring and sharing the high quality teaching resource.

In order to improve educational quality of Chinese college, the Ministry of Education of the People's Republic of China have also paid close attention to applying information technology in high education and have carried the plan of National resource sharing class in 2011. So far, there are hundreds of on-line opening courses, in China. Some of opening courses have been accepted for studying by students from different college, but most of these courses were low utilization because of average performance. Due to lacking versatile making-team and masterly lecturers, most opening courses have a few users on internet. What are the Chinese opening courses in trouble? The main reason is that most of Chinese teachers do not know much about constructing teaching platform taking advantage of information technology so that the visual effects of the homepage and pattern of manifestation and editing effect of their teaching video are too insipid to attract the students. Our previous studying show that a skilled making-team, Professional filming and editing device, arranged class room, unified course design, and masterly lecturers are crucial to produce the attractive videos and then construct an artistic homepage. This paper will introduce the key technique of making teaching video and the integrated workflow of constructing the teaching platform with surprising effects which would attract more Chinese students.

\section{THE WORKFLOW OF CONSTRUCTING PLATFORM}

The Construction of teaching platform based on Internet is a kind of systematic project. The excellent working teams will design the integrated workflow at first, which could make the followed job more organized and obtain twofold result with half the effort. In our previous research, a practical workflow of constructing teaching platform are set up, which have not only saved our many investment and working time, but also produced an unexpected attraction on our web site. Every step in our workflow is necessary for making a qualified teaching platform. Some inessential Processes have been excluded out of the workflow by designers, because an excess of redundant will increases costs or waste time and energy, but contributing little to platform, so it is unworthy of trying hard for a little progress. And some more important steps, such as filming, need to spent more time and energy, never cut corners on this, because the video are the focuses of students when they studying your lessons. It will consume the $35 \%$ time and energy of all, often. 


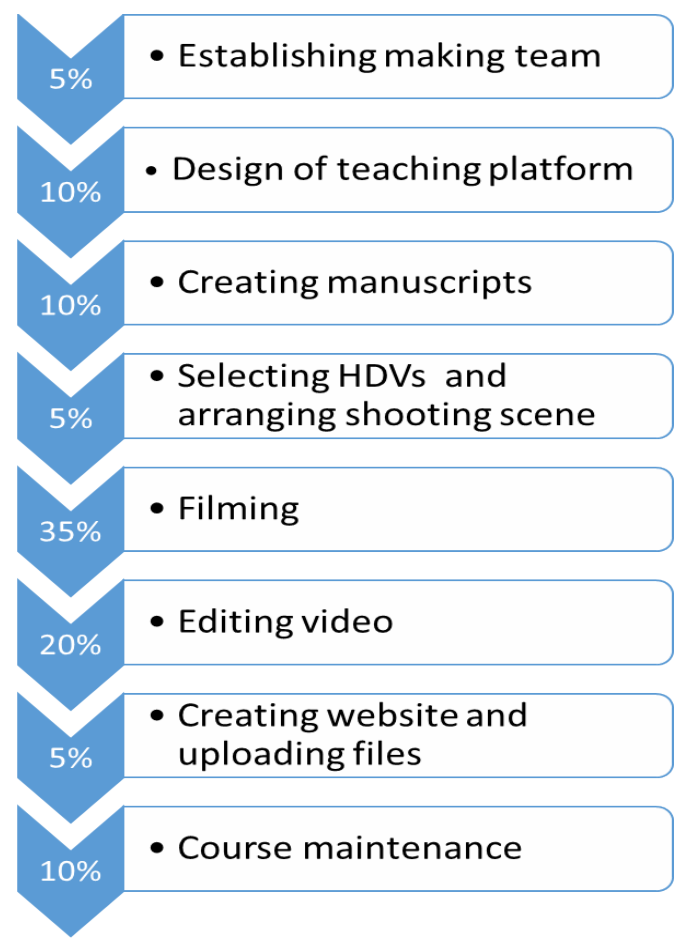

Fig1. THE WORFLOW OF CONSTRUCTING TEACHING PLATFORM. PERCENTAGE REPRESENT THE PROPORTION OF TIME AND ENERGY SPENDING ON CORRESPONDING STEP.

\section{ESTABLISHING MAKING TEAM AND DESIGNING THE PLATFORM}

According to our experience in the previous research, a capable making-group could produce attractive teaching platform. Members with kinds of strong point of information technology are necessary in the group, such as teachers, Director, cameraman and video editors. Teachers take charge of global planning, course arranging and lecture. Director takes charge of planning filming program, conceiving the plots, arranging the scenes, guiding Cameramen and video editors. Cameramen take charge of filming. Video editors take charge of editing camera and making caption, audio and Video FX.

Experimental teaching is essential in most science and engineering courses. Manuscript editor, experiment operator, dubbing specialist and logistics workers are the kind of necessary members additional in you group when you plan to produce an experimental teaching part because this section need to emphasizing experimental detail and experimental phenomena. Manuscript editor take charge of arranging sequence of shooting unit, conceiving the detail of video and writing shooting manuscript or narrate manuscript. Experiment operator who play the role as the actors demonstrate experimental process in indicating video. Dubbing specialist provide the voice in the video. Logistics Workers arrange scene and provide experimental instruments before filming [2].

\section{CREATING MANUSCRIPT AND ARRANGING FILMING SCENE}

\section{A. Making PowerPoint and manuscript}

PowerPoint can make students understand the content of lecture easily. But most teachers are not good at making
PowerPoint, which is too garish to emphasize on subject. In our investigation, the simple template with pastel colors will catch student's more attention when lecturing. Some common Principles should be applied when you making teaching PowerPoint. For example, the course name, Modules name or orders should be arranged in suitable location on one page of PowerPoint. Everything uncorrelated to you lecture should be ruled out from the background of pages. Words with consistent fonts and font size should be used in the different chapters, which make the page looks clear and uniformed. The different fonts and font size in corresponding grade of chapter should locate in the same position in every pages. No more than four kinds and 150 words in every page, and apparent chromatism between word and background are necessary. Boldface, italics, New Wei, official script with 32 pounds in title and not less than 24 pounds in body will make students feel well, and Simplified Chinese are usually used. The Punctuation could not be located in the head of line; the first half of quotation marks, parenthesis or book title marks should not locate in the tail of lines and the after half of which not in the head of lines; Dashes and ellipses should account for two characters. Connectives and space marks account for one character normally. Page spacing should be not less than 1.2 folds. The lines should be bold in a table.

\section{B. Writing filming script and dubbing script for experimental teaching video}

A teaching video of experimental procession consist of experimental subject, experimental purposes, experimental principle, experimental equipment, experimental operating process and precautions. During the filming, experimental flow should be split to different shot calls, and not making smooth. The filming sequence and filming detail should be designed before filming. When necessary, close-up shot could be design in filming scheme to display accurately experiment. Filming script with information above need to be created by makinggroup, which is reference in filming and video editing. Besides of information above, more details about filming, such as background, shooting angle, duration of a shot, should be arranged reasonable in lines of script.

Narratage is the explanation and additional indication to the contents of teaching video. Dubbing script with simple and professional words, clear and straightaway expression would be prepared for dubbing specialist before taping.

\section{C. arranging specialized filming scene}

In a professional teaching video, clear lectures would make students understanding easily about the content of course. More often, filming is proceeded in a professional filming room with area of 100 to 400 square meters. In order to reducing the environment noise, no more than $40 \mathrm{~dB}$ normally, noise-proofing device should be located inside the door of the classroom. The unsuited setting would reduce the quality of frames, Such as white or black colored background, table and chair will produce reflective or shining. The backplane hanging landscape painting would increase the digital amount and produce poor quality of film [3]. So, these adverse things should be as far as possible to be ruled out 
before filming. Some practice would increase the screen effect, such as engineering projector with 5000-8000 lumens is conducive to high quality picture. If necessary, RPTV or LCD TV instead of projector would produce more perfect frames. Another way to increasing film quality is employing professional HDVs with 700-800 TV Line, SNR 60dB above, and sensitivity at $1080 / 50 \mathrm{i}$ is not less than F12. ATW function of HDVs is helpful to an amateur. Wireless microphone connecting with HDVs is necessary for improving audio quality. But communications equipment will interfere with the transmission of electric signal, so it must be turn off.

\section{FILMING AND EDITING VIDEO}

When filming for a lecture, in order to record all the figures, no less than three HDVs are set in different position of classroom (Fig 2). The firs HDV is set at the back of the room, which recording the whole scene or distant view, the second is set at the right or left middle of the room, which recording the close shot, the third is set at the right or left front of the room, which recording the students. And one of HDVs is not located in the view of other two. If projector is used during lecture, the active range of teacher should be outside the range of exposure, otherwise, the face or body of teacher is likely overexposure by projector and shadow would produced on projection screen, which would make viewers feel uncomfortable.

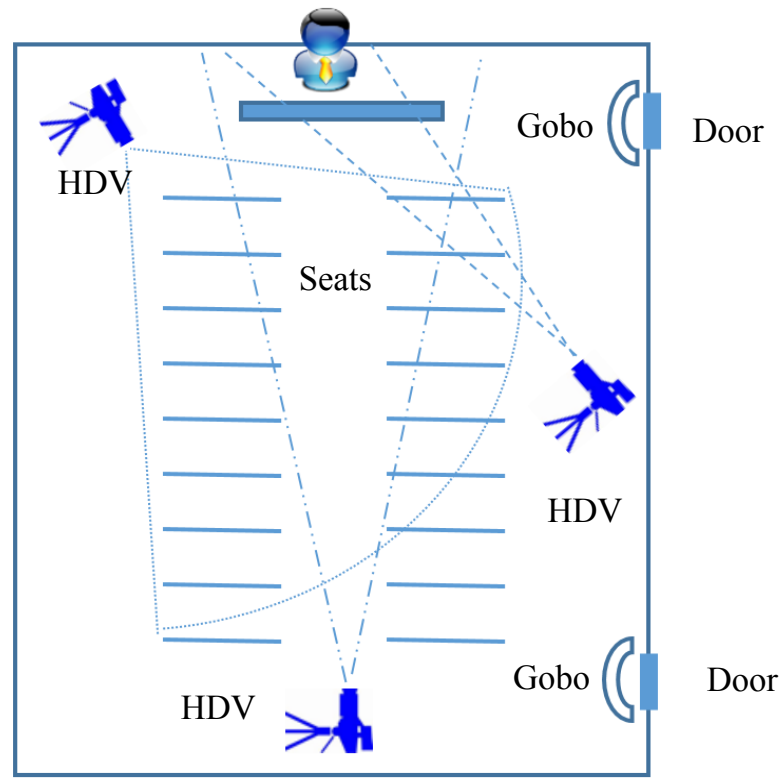

Fig 2.THE AREA OF THE ROOM IS 100 TO 400 SQUARE METERS . GOBO LACATE INSIDE THE DOOR OF ROOM.THE FIRS HDV IS SET AT THE BACK OF THE ROOM, WHICH RECORDING THE WHOLE SCENE OR DISTANT VIEW; THE SECOND IS SET AT THE RIGHT OR LEFT MIDDLE OF THE ROOM, WHICH RECORDING THE CLOSE SHOT; THE THIRD IS SET AT THE RIGHT OR LEFT FRONT OF THE ROOM, WHICH RECORDING THE STUDENTS. ONE OF HDVS IS NOT LOCATE IN THE VIEW OF OTHER TWO.

When filming for an experiment procession, one or two HDVs are enough. Segmented filming would process according to the script, and then assemble these story boards in the editing procession. If you intend to exhibit the detail action of a special experimental procession, Close-up is a good choice.

After filming, editing video is a more important job. The nonlinear editing system has enormous advantages in the teaching video editing, which consist of nonlinear editing card, work station, editing software and could promptly access frame or file of video from and to computer disc directly. When editing story boards, the redundant or muffed videos should be cut off. We can convert the PowerPoint to a series of pictures and then insert it to video if you do not like the effect of filming from the projection screen directly. Inserting picture of PowerPoint could make the screen looks more artistic. Narratage should be taped in advance by dubbing specialist, if you dislike the sound from the filming local. The narratage need to be combined with the action in video. There are more other video editing techniques such as Flash, Magic Camera, Video Transitions, video rendering and so on. If necessary, you can try in your video. When compressing the film, Sampling at $48 \mathrm{KHz}$ is appropriate, or else the transmission speed or image quality will be not better.

\section{CREATING TEACHING PLATFORM AND UPLOAD FILES}

\section{A. the framework of teaching platform}

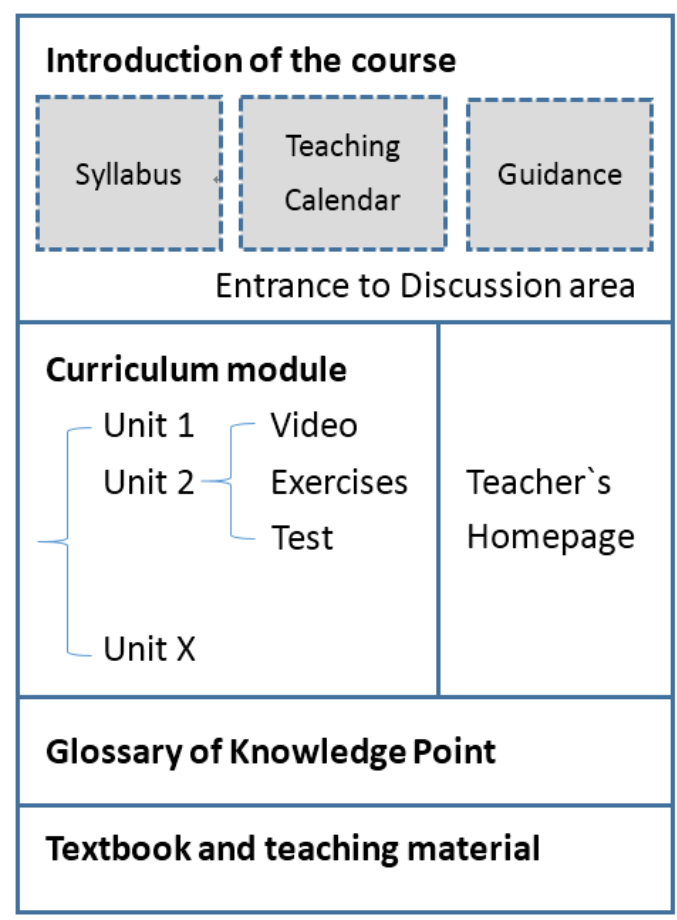

Fig3.FRAMEWORK OF PLATFORM

An attractive and simply framework are important to improve the click rate. The platform with all the necessary subjects of your course could be divided into different areas and identical kind of content had better been placed in the same area. Every area of your platform need to be arranged more harmonious and apparently to make sure that students can caught sight of it easily. But the real situation are just apposite, The pages of some opening course are designed too 
garish and clutter, so that students will feel bored when looking for the expected. And some others designed too simple and barren so that your can find nothing. Our platform (Fig 3) is popular with students. If there is not a more better design in your mind, you can try it.

\section{B. the method of uploading}

If the platform with the individual character of the course is finished, you can upload the video, PowerPoint and other teaching files necessarily. Most teachers will get into trouble when producing the course introduction and guideline, which provide students advanced understanding. Messy code may produce when you directly copy the content from Word editor to on-line Editor because of compatibility problem, so you need to type word in Editor directly or copy the content from Word editor to TXT editor and then copy it from TXT editor to on-line Editor. Other files of no more than $1 \mathrm{~GB}$ in capacity could be uploaded directly [4]. The content of PowerPoint must be according with videos of no more than $2 \mathrm{~GB}$ in capacity and less than an hour in duration. And, in order to make you course site more active, you can upload the expand material such as example library, seminar library, test paper, and regarding links.

\section{SURVEY IN STUDENTS}

In order to assess our teaching platform, we had done the questionnaire survey randomly among different of grades (fig 4). More than $70 \%$ students are more prefer our teaching platform. These students would review the video on line before they went to classroom. A lot of students including many no-supporting-students admitted that beforehand on-line learning make them understand more easily than before. When being asked the impression about the homepage of platform, most students think that they could find most of knowledge easily, and the exhibition in the video is vivid, simple but profound, and mostly they can study long without feel boring.

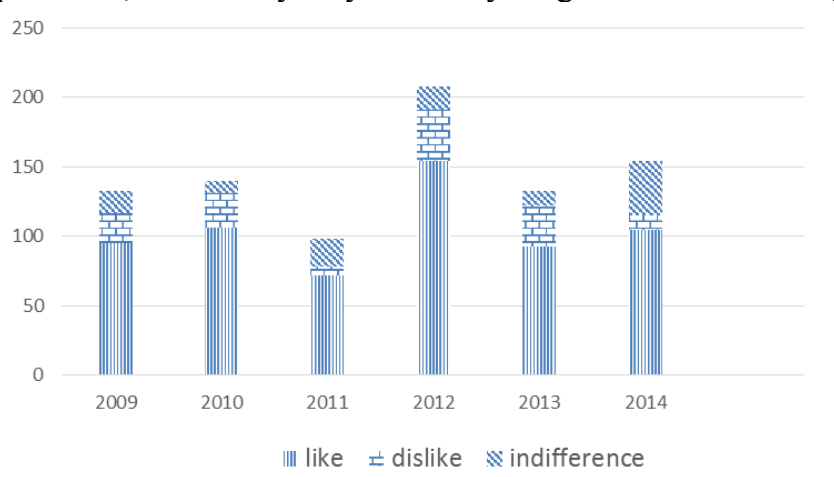

Fig4. THE RANDOMLY QUESTIONNAIRE SURCEY IN SIX GRADES. ABSCISSA IS GRADE OF STUDENTS INVOLVED IN THE INVESTIGATION AND ORDINATE IS THE NUMBER OF STUDENTS.

\section{CONCLUSION}

Leading by famous university, opening courses are spring up like mushrooms all of the word. The universities in China are starting join the campaign of constructing opening teaching platform with positively impetus under the Ministry of Education. Because of late starting comparing with the famous university in the word, the step of constructing opening teaching platform are at the early stage. Most students are used to the traditional learning methods in the classroom and they are still not strong interest in the opening course. In order to attract more students to employ the better learning manner, we must improve the quality of opening teaching platform. But, most of teachers are not good at it. They have simply moved the classroom to the internet with no top-level design, no artistic screen, not interaction with students even and most of platform are lacking of long-term maintenance. By long term experience, our teaching platform, produced according the workflow recommended in this paper, with well-designed homepage, lively narrating, carefully demonstrating in experiment procession and vivid video with special effects, have attracted more students from different universities. Moreover, insisting to interact with students is another factor of our success.

\section{ACKNOWLEDGMENT}

We indebted to $\mathrm{Mr} \mathrm{P}$. Zhang (center of educational information technology, Jilin University) for technical assistance with filming, video editing and for his help in classroom arrangement, to higher education press of China for the assistance with the information platform and to other teachers in our group for their hard work and regardless of Fame. This work is supported by the fund of Jilin university educational reform project (2014)--Project of developing teaching ability of young teachers.

\section{REFERENCES}

[1] Q.L.Gu, Q.Wang, Z.Y.Yu, Exploring How to Constructing the Openning Course of Environmental Biology,Anhui Agri. Sci. Bull.vol.23,pp. 168-170,2012.

[2] H.F.Tang, Y.Liu, W.Meng, The Exploration of National Quality Open Course for Basic Bio-experiments, Biology Teaching in University(Electronic Edition),vol.1,pp.7-11,2014.

[3] H.Zhu, Exploring How to Constructing and Using Recording Classroom under New Situation, Net Friend World, vol.3, pp. 28-29, 2013.

[4] J.Zhang, X.Q.Long, W.Ma, The Using Technique of Uploading Tools of National Quality Open Course, Education Teaching Forum, vol.29, pp. 277-278, 2013. 